\title{
A New Formula for Hydrogen Consumption in Hybrid Systems Based on Fuel Cell Current Gradient and Peak Value
}

\author{
Yasin Özçelep (D), Gürcan Sarı iD, Ayten Kuntman \\ Department of Electrical and Electronics Engineering, İstanbul University-Cerrahpaşa, İstanbul, Turkey
}

Cite this article as: Özçelep Y, Sarı G, Kuntman A. A New Formula for Hydrogen Consumption in Hybrid Systems Based on Fuel Cell Current Gradient and Peak Value. Electrica, 2019; 19(1): 59-64.

\section{ABSTRACT}

In the study, we proposed a new formula for the hydrogen consumption of fuel cell under non-constant current behavior. We used supercapacitors as auxiliary energy source to form a hybrid system and change the current behavior of the fuel cell. We performed hybrid system tests for different supercapacitor values. We extracted the fuel cell current, voltage, hydrogen consumption for each configuration. We compared the measured values and expected values from known equations. We see that, results from hydrogen consumption equations does not match the hybrid system hydrogen consumption. Finally, we proposed a new formula for hydrogen consumption including the current gradient and current peak value for hybrid systems.

Keywords: Hydrogen fuel cell, hydrogen consumption, hybrid systems

\section{Corresponding Author: \\ Yasin Özçelep}

\section{E-mail:}

ycelep@istanbul.edu.tr

Received: 14.08 .2018

Accepted: 20.11 .2018

(c) Copyright 2019 by Electrica

Available online at

http://electrica.istanbul.edu.tr

DOI: 10.26650/electrica.2019.18013

\section{Introduction}

Due to advantages as low temperature, high energy density, small size and environment friendly clean energy; proton exchange membrane fuel cells (PEMFC) are considered to be one of the promising energy sources for the hydrogen fuel cell powered vehicles [14]. Besides the advantages, PEMFCs have some electrical disadvantages as poor dynamic response, low power density [5-7]. These disadvantages cause increase in hydrogen consumption and consumption related efficiency of the PEMFC. To suppress the effects of disadvantages, a hybrid powertrain is formed by using the PEMFCs with an auxiliary power source [5]. To form a hybrid powertrain mostly batteries and supercapacitors are used as an auxiliary power source [8-11].

Because of the purpose of forming hybrid powertrain reducing the hydrogen consumption, the hydrogen consumption, should be calculated in the design stage of the powertrain. Thus, the best solution can be achieved considering the size and the cost of the powertrain. The mathematical equations proposed by the authors [12-15] to calculate the hydrogen consumption of the fuel cell stack. The molar hydrogen consumption of the fuel cell is given in equation 1 [12-13];

$$
n=\frac{I \cdot N}{2 F}
$$

Here, $\mathrm{I}$ is the current and $\mathrm{N}$ is the cell number of the fuel cell stack. $\mathrm{F}$ is faraday constant, approximately $9.65 \times 10^{4} \mathrm{Cmol}^{-1}$. And $\mathrm{n}$ gives the molar hydrogen consumption. Using equation (2) hydrogen consumption in Ipm (liter per minutes) can be calculated [14-15];

$$
l p m=0.00735 x \operatorname{IxN} x S_{\mathrm{H}_{2}}
$$

Here, $\mathrm{I}$ is the current and $\mathrm{N}$ is the cell number of the fuel cell stack. $\mathrm{S}_{\mathrm{H} 2}$ is stoichiometric ratio for hydrogen. 
In both equations, the consumption formula is dependent the time-independent value of the current. The equations do not contain how the current reaches this value. The current signal of the fuel cell stack will be changed by auxiliary power source, while the reducing hydrogen consumption and these equations cannot be used for calculating the hydrogen consumption.

In the study, we formed a hybrid powertrain using supercapacitors as auxiliary power source by connecting the fuel cell and supercapacitors parallel to each other. We performed our tests on a prototype hydrogen powered vehicle. We used different supercapacitor values in repeating tests and recorded the voltage, current and hydrogen consumption values during each test. Using measured results, we proposed a new hydrogen consumption formula including the fuel cell current gradient and peak value. The performed tests also provided us to determine the best configuration considering the hydrogen consumption.

\section{Material and Method}

We performed test in a prototype hydrogen powered vehicle. The system components are given in Table 1.

Table 1. System components

\begin{tabular}{ll}
\hline Description & Specification \\
\hline Fuel Cell & $700 \mathrm{~W}, 40$ cells, 37V/25A \\
\hline Electrical Motor & $500 \mathrm{~W}$, nominal voltage 48V \\
\hline & $\begin{array}{l}\text { Each one 2.7V, 360F; in each test 18F, } \\
\text { 36F and 54F supercapacitor banks are } \\
\text { used }\end{array}$ \\
\hline Supercapacitor & 200kg with driver \\
\hline W: watt; A: ampere; V: volt; F: Farad; kg: kilogram
\end{tabular}

Firstly, we performed a test without using supercapacitors for reference values. After reference measurements, we formed hybrid powertrain as in Figure 1.

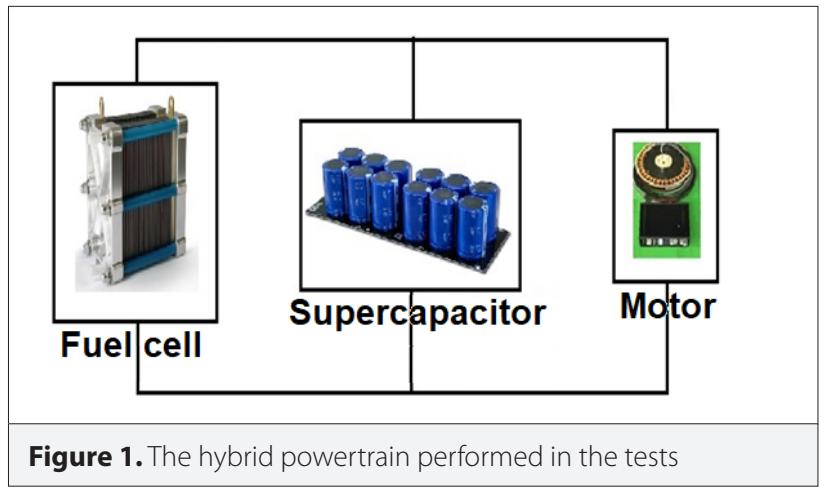

We performed same tests for supercapacitor values $18 \mathrm{~F}, 36 \mathrm{~F}$ and $54 \mathrm{~F}$. We measured the hydrogen consumption using Red-y flow meter.

\section{Results}

Figure 2 presents the fuel cell currents in hybrid powertrain with different supercapacitor values.

As seen in Figure 2 the peak value and gradient of the current curve changes depend on the supercapacitor value. The peak value and gradient of fuel cell current decrease with the increasing supercapacitor value. The hydrogen consumption of fuel cell is measured $2.85 \mathrm{~L}$ for test without using supercapacitors and for hybrid power train $2.54 \mathrm{~L}, 2.45 \mathrm{~L}$ and $2.28 \mathrm{~L}$, for $18 \mathrm{~F}, 36 \mathrm{~F}, 54 \mathrm{~F}$ respectively.

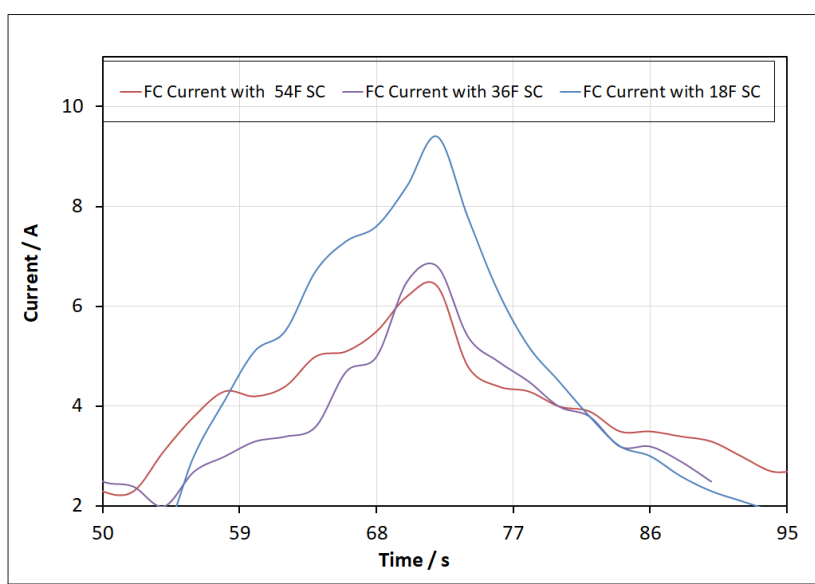

Figure 2. The fuel cell current for different supercapacitor values

After these results, we investigated relation between the measured hydrogen consumption and expected hydrogen consumption from equations current value directly determines the hydrogen consumption.

Firstly, we extracted peak current and hydrogen consumption curve (Figure 3 ) and see that, while peak current decreased around $60 \%$, hydrogen consumption decreased only $20 \%$.

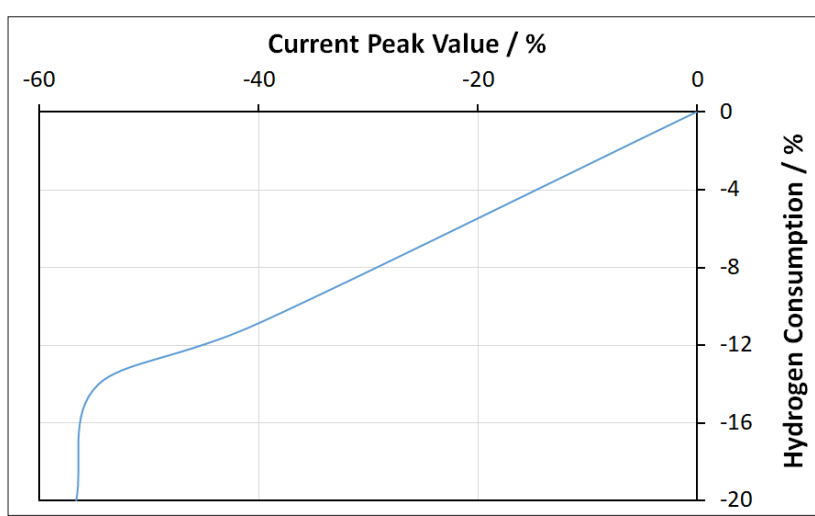

Figure 3. Hydrogen consumption and fuel cell peak current relation 
Sure, the fuel cell does not deliver the peak current constantly during operation because of hybridization with supercapacitors, the conflict between measured and expected value can make sense. To remove the conflict and make the equations useful, we calculated the average value of the current by fitting mathematical equations to current curves. The hydrogen consumption and average current curve is presented in Figure 4. As seen in Figure 4 while the average current decreases nearly $70 \%$, the hydrogen consumption is only decreased $20 \%$. Here, there is a need for a new formula for non-constant currents which includes the gradient of current. We proposed a new formula which includes both peak value of the current and the gradient of the current.

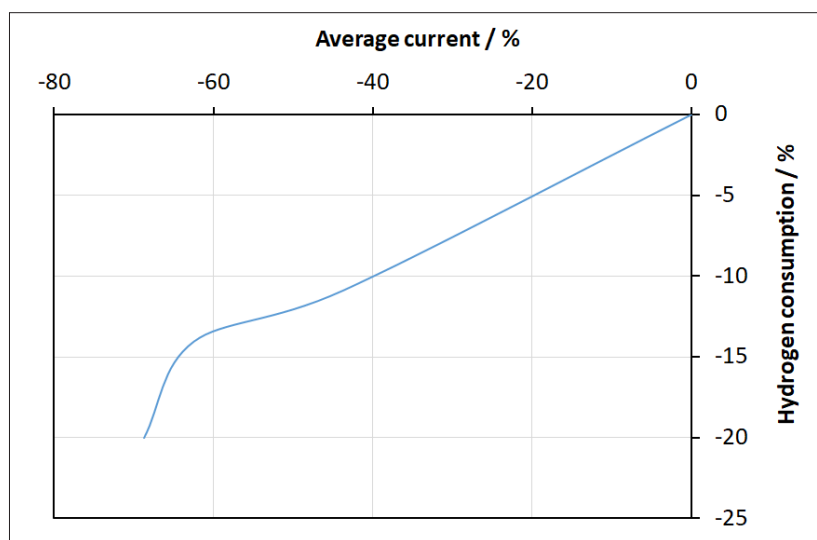

Figure 4. Hydrogen consumption and fuel cell average current relation

To form a new formula, we normalized the hydrogen consumption according to peak value of current and presented in Figure 5.

The mathematical equation of the curve in Figure 5 is expressed in equation 3 .

$$
H_{n c p}=-0.5062 x I_{p}^{-0.767}
$$

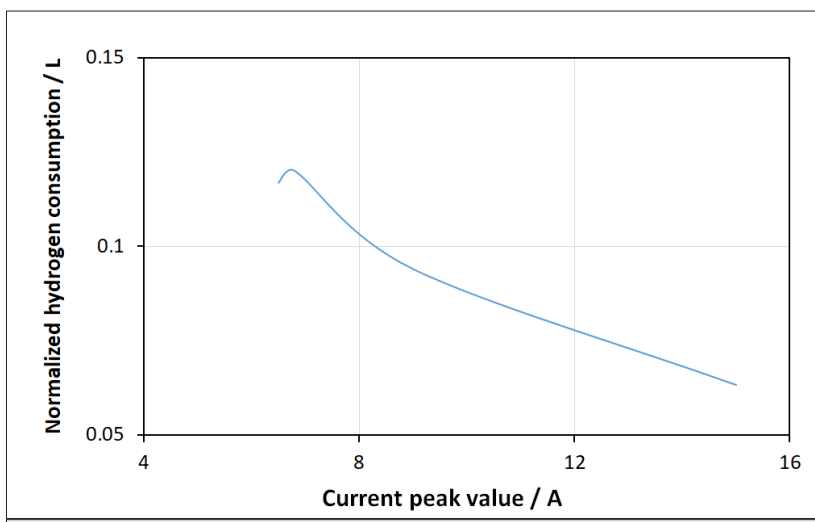

Figure 5. Normalized hydrogen consumption according to current peak value
Here, $\mathrm{H}_{\text {ncp }}$ stands for normalize hydrogen consumption according to peak value of the current and $I_{p}$ is the peak current value.

We attributed the remaining hydrogen consumption to current gradient induced consumption and presented the consumption- current gradient curve in Figure 6.

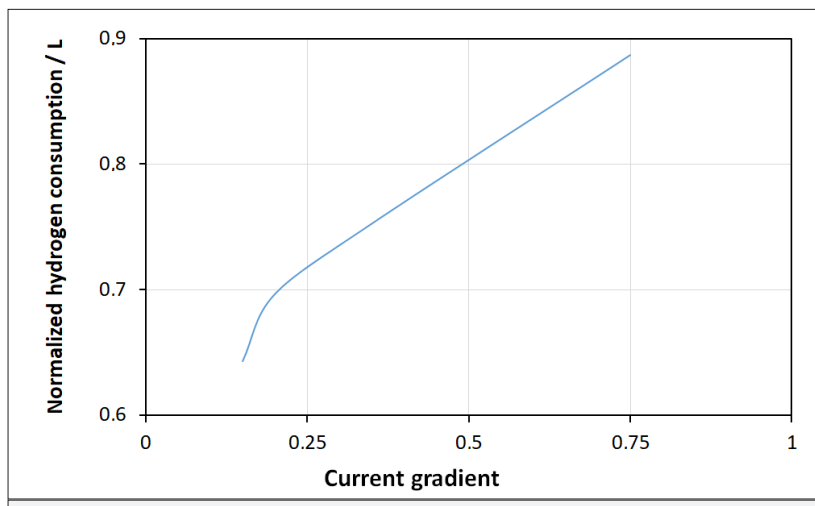

Figure 6. Normalized hydrogen consumption according to current gradient

The mathematical equation of the curve in Figure 6 is expressed in equation 4 .

$$
H_{n c g}=0.9334 x G^{0.1924}
$$

Here, $\mathrm{H}_{\mathrm{ncg}}$ stands for normalize hydrogen consumption according to current gradient and $\mathrm{G}$ is the current gradient.

After determining the normalized consumptions, equation 3 and equation 4 combined as in equation 5 to form hydrogen consumption.

$$
H_{C}=k_{1} x\left(I_{p} x G\right)^{k_{2}}
$$

Here, $\mathrm{H}_{\mathrm{c}}$ stands for hydrogen consumption $(\mathrm{L}), \mathrm{k}_{1}\left(\mathrm{LA}^{-1}\right)$ and $\mathrm{k}_{2}$ are the constants. $I_{p}$ is the peak value and $\mathrm{G}$ is the gradient of the current. In equation $5, \mathrm{k}_{1}$ and $\mathrm{k}_{2}$ are 0.7755 and 0.0837 ; respectively.

To validate the results of curve fitting method, we compared the measured and calculated results as seen in Figure 7. The calculated results are in a good agreement with measured results.

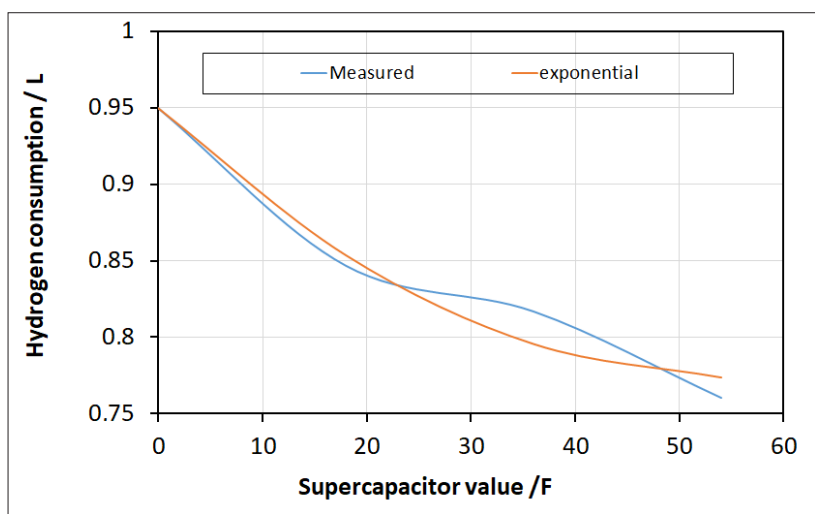

Figure 7. Comparison of measured and calculated results 
Because of the peak value and the current gradient are change with supercapacitors we extracted the peak value and current gradient changes with supercapacitors. The peak current-supercapacitor curve is seen in Figure 8.

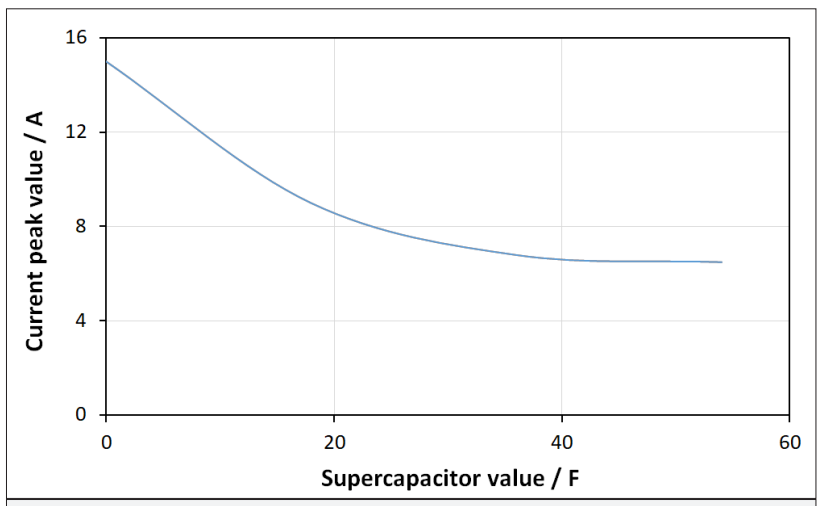

Figure 8. Current peak value change with the supercapacitors

We formulated the supercapacitor induced change in peak current as in equation 6 , using curve fitting methods.

$$
I_{p}=21.52 x C^{-0,308}
$$

Here, $I_{p}$ is the peak current and $C$ is the supercapacitor value.

The current gradient-supercapacitor curve is seen in Figure 9.

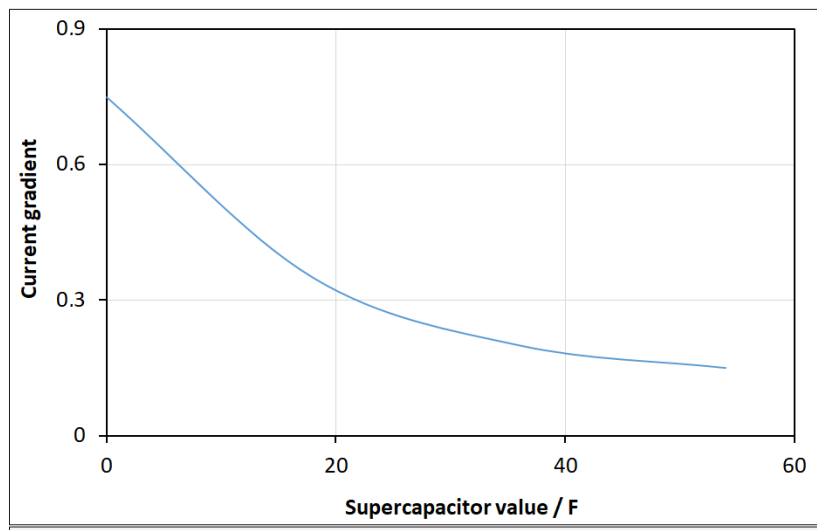

Figure 9. Current gradient change with the supercapacitors

We formulated the supercapacitor induced change in current gradient as in equation 7 , using curve fitting methods.

$$
G=3.27 x C^{-0,775}
$$

Here, $G$ is the current gradient and $C$ is the supercapacitor value.

If equation 6 and 7 put into proposed hydrogen consumption equation, the supercapacitor effect on hydrogen consumption can be extracted for hybrid systems.

\section{Conclusion}

In the study, we proposed a new formula for the hydrogen consumption for hybrid systems. We used supercapacitors as auxiliary energy source to change the current behavior of the fuel cell. We performed tests on hydrogen powered vehicle for different supercapacitor values and for each test we extracted different current behavior. Using experimental results, we formed a new formula in exponential form, including peak current and current gradient. Seen in normalized hydrogen consumption curves, using supercapacitors decreases the peak current but increases the normalized hydrogen consumption. The increasing supercapacitor value decreases both the current gradient and hydrogen consumption. A new hydrogen consumption formula for hybrid systems is proposed which includes the supercapacitor induced peak current and current gradient changes. This study helps designers to find the best solution for size and the cost of the powertrain considering the hydrogen consumption at design stage.

Peer-review: Externally peer-reviewed.

Conflict of Interest: The authors have no conflicts of interest to declare.

Financial Disclosure: The authors declared that this study has received no financial support.

\section{References}

1. Y. Hou, C. Shen, D. Hao, Y. Liu, H. Wang, "A dynamic model for hydrogen consumption of fuel cell stacks considering the effects of hydrogen purge operation", Renew Energy vol. 62, pp. 672-678, 2014. [CrossRef]

2. M. Uzunoglu, M. S. Alam, "Dynamic modeling, design, and simulation of a combined PEM fuel cell and ultracapacitor system for stand-alone residential applications", IEEE Trans Energy Convers, vol. 21, pp. 767-775, 2006. [CrossRef]

3. D. Shin, K. Lee, N. Chang, "Fuel economy analysis of fuel cell and supercapacitor hybrid systems", Int J Hydrogen Energ, vol. 41, pp. 1381-1390, 2016. [CrossRef]

4. P. Ahmadi, E. Kjeang. "Realistic simulation of fuel economy and life cycle metrics for hydrogen fuel cell vehicles", Int J Energy Res. Vol. 41, pp. 714-727, 2017. [CrossRef]

5. Y. Hames, K. Kaya, E. Baltacioglu, A. Turksoy, "Analysis of the control strategies for fuel saving in the hydrogen fuel cell vehicles", Int J Hydrogen Energ, vol. 43, no. 23, pp. 10810-10821, June 2018. [CrossRef]

6. G. Sarı, Y. Özçelep, A. Kuntman, "On the optimum powertrain configuration of fuel cell powered vehicle for minimum hydrogen consumption", $9^{\text {th }}$ International Conference on Electrical and Electronics Engineering (ELECO) Turkey, 2015, pp. 379-382. [CrossRef]

7. C. Kunusch, F. Castaños, "Extremum seeking algorithms for minimal hydrogen consumption in PEM fuel cells", American Control Conference (ACC), 2013, pp. 1144-1149. [CrossRef]

8. B. Morin, D. V. Laethem, C. Turpin, O. Rallières, S. Astier, A. Jaafar, O. Verdu, M. Plantevi, V. Chaudron, "Direct hybridization fuel cell-ultracapacitors", Fuel Cells Vol 14, pp. 500-5007, 2014. [CrossRef]

9. H. Fathabadi, "Novel fuel cell/battery/supercapacitor hybrid power source for fuel cell hybrid electric vehicles", Energy, vol. 143, pp. 467-477, 2018. [CrossRef] 
10. Q Li, W. Chen, Y. Li, S Liu, J. Huang, “Energy management strategy for fuel cell/battery/ultracapacitor hybrid vehicle based on fuzzy logic", Int J Elec Power, vol. 43, pp. 514-525, 2012. [CrossRef]

11. M. Uzunoglu, M. S. Alam, “Dynamic modeling, design and simulation of a PEM fuel cell/ultra-capacitor hybrid system for vehicular applications", Energ Convers Manage, vol. 48, 1544-1553, 2007. [CrossRef]

12. A. Kabza, "Fuel Cell Formulary, can be found under" http://pemfc. de/FCF_A4.pdf, 2016.
13. J. Larminie, A. Dicks, "Fuel Cell Systems Explained", John Wiley \& Sons, 2003. [CrossRef]

14. M.R.B. Mustaffa, W.A.N.B.W. Mohamed, R.B. Atan, "Analytical approach to predict hydrogen consumption of a lightweight PEM fuel cell vehicle", IEEE International Conference on Control System, Computing and Engineering (ICCSCE), 2012, pp. 489-494. [CrossRef]

15. F. Barbir, "PEM fuel cells: Theory and Practice", Elsevier Academic Press, California, USA, 2005. 


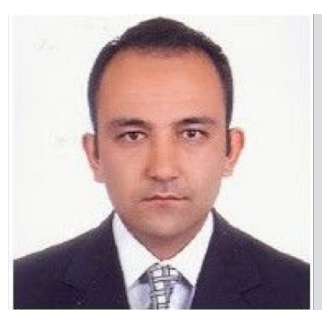

Yasin Özçelep received the B.Sc., M.Sc. and PhD. degrees from Electrical and Electronics. Department, Istanbul University, Istanbul, Turkey, in 2002, 2004 and 2009, respectively. He is working as Associate Professor in same department. His research interests are hydrogen fuel cells, hydrogen powered vehicles, semiconductor device and circuit reliability, reliability modeling and electronic circuits.

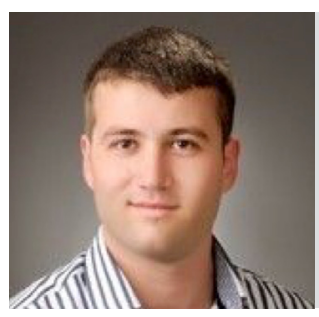

Gürcan Sarı received the B.Sc. and M.Sc. degrees from Electrical and Electronics Department, Istanbul University, Istanbul, Turkey, in 2014 and 2017, respectively. He was the team leader of Istanbul university Hydrogen Powered Vehicle (HIDROIST).

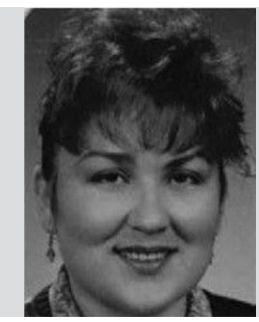

Ayten Kuntman received her M.Sc. degree from Istanbul University in 1979 and her Ph.D. degree from Istanbul Technical University in 1989, respectively. In 1980 she joined the Electronics and Communication Engineering Department of Istanbul Technical University. From 1995 to 2001 she was an associate professor of Electrical Power Systems in the Electrical and Electronics Engineering Department of Istanbul University. Since 2001 she is a professor of Electrical Power Systems in the same department. Her research interest include dielectric properties of polymers, semiconductors, aging of cable polymers, microelectronics technologies, hydrogen fuel cells, thermodinamic properties of polymers and reliability of materials. Dr. Kuntman has authored many publications on polymers, semiconductors and microelectronics technologies. 